\title{
PREVALENCE AND IMPACT OF DYSMENORRHEA IN THE FIRST YEAR MEDICAL STUDENTS OF AHMEDABAD
}

Jayun M. Joshi, Bansi K. Davda, Manish M. Jadav.

1. Assistant Professor. Department of Obstetrics \& Gynaecology, LG Hospital,

2. Junior Lecturer. Department of Community Medicine, NHLMMC.

3. Professor \& Head. Department of Obstetrics \& Gynaecology, NHLMMC.

\section{CORRESPONDING AUTHOR:}

Dr. Jayun Joshi,

24, Jagatjanani Society,

Behind Polytechnic, Ambawadi,

Ahmedabad - 380015.

E-mail: drjmjoshi@gmail.com

Ph: 00919427711313

ABSTRACT: Dysmenorrhea is the painful menstruation mostly accompanied by the number of other symptoms which are disturbing to herself. The purpose of the study was to determine the prevalence of dysmenorrhea in first year medical students and its impact on their academic and personal activities. STUDY DESIGN: Cross sectional study MATERIALS AND METHODOLOGY: Subjects are asked to complete the given questionnaire handed out by researcher. The predesigned and pretested questionnaire included questions regarding sociodemographic information, menstrual pattern, severity with grading, associated symptoms and impact of dysmenorrhea. RESULTS: The prevalence of dysmenorrhea was $87 \%$. The most common symptoms were mood changes, backache and stomach cramps. Only $2.7 \%$ had severe dysmenorrhea. The most common management strategy practiced was the rest (93.7\%). Only 17.4\% had consulted doctors for their complaints. CONCLUSION AND RECOMMENDATION: Dysmenorrhea is the significant public health problem in women's life. It has great impact on personal and social life. Adolescent girls should be motivated to consult the doctor for their disturbing menstrual problems.

KEY WORDS: Dysmenorrhea, premenstrual syndrome (PMS), first year medical students.

INTRODUCTION : Dysmenorrhea is a painful and cramping sensation in the lower part of the abdomen often accompanied with the other biological symptoms including fatigue, dizziness, sweating, headache, backache, nausea, vomiting, diarrhea and other symptoms just before or during menses. Dysmenorrhea could be primary and secondary on the basis of presence or absence of pathology. Primary dysmenorrhea is seen only in ovulatory cycles usually developing within 6 to 12 months of menarche with no pathology or organic base. The pain in the Primary dysmenorrhea and the systemic symptoms that may be associated with it are due to high prostaglandin level.

The level of the prostaglandin F2 $\alpha$ are high during the first two days of menstruation in women found to be higher in women with severe menstrual pains than in women who experience mild or no menstrual pain.

Secondary dysmenorrhea is usually due to pelvic pathology and it is not common in adolescent girls. However some girls may suffer secondary dysmenorrhea following pelvic inflammatory disease. The mechanism responsible for pain in the secondary dysmenorrhea 
varies and may not involve the high level of prostaglandins. The diagnosis of dysmenorrhea is generally clinical. Accurate history and examination can make the diagnosis easier.

Some of the symptoms associated of the severe form of dysmenorrhea are common to premenstrual syndrome(PMS) as both the condition have no organic base. Premenstrual syndrome(PMS) is recurrent variable somatic, psychological and emotional symptoms that develop during the 7-14 days before onset of menstruation in women who are mainly aged 20-40 years. Over 150 different symptoms have been linked to premenstrual syndrome (PMS) but the most common are fatigue, headache, mood changes, inability to concentrate etc. the symptoms in the premenstrual syndrome (PMS) are due to variation in the sex steroids and low circulation serotonin levels which differs from the high levels of prostaglandins seen in primary dysmenorrhea.

MATERIAL AND METHODS: The cross sectional study was conducted in the specific group consisting of first year medical students of various medical colleges of Ahmedabad. The target group was chosen to determine the prevalence of dysmenorrhea in that group, impact of dysmenorrhea on their routine activities, treatment modalities they prefer and also to give them related education regarding menstrual problems.

After choosing the target group the necessary permission was taken from concerned authority for conducting this study. The meeting was held and the questions were discussed with them. As the target group was medico, the study was easier and accurate. They had given 15 minutes to voluntarily complete the questionnaires.

\section{The questionnaire}

1. Form No. :

2. Age :

3. Age of Menarche :

4. Duration of cycle: $\quad$ (1) $<3$ days (2) $3-5$ days $\quad(3)>5$ days

5. Interval $b / w$ two periods : $\quad$ (1) $<21$ days (2) $21-34$ days (3) $>34$ days

6. Bleeding amount (pads used/day): (1) $1 /$ day $\quad$ (2) $2-4 /$ day $\quad$ (3) $>4 /$ day

7. Grading of severity in dysmenorrhea :

1) No dysmenorrhea

2) Mild (painful but not inhibits normal activity)

3) Moderate (daily activity affected and required analgesics which gives relief)

4) Severe (activity clearly inhibited and poor effect of analgesics)

8. Associated symptoms:

$\begin{aligned} \text { I. } & \text { Stomach cramps } \\ \text { II. } & \text { Backache } \\ \text { III. } & \text { Mood changes } \\ \text { IV. } & \text { Fatigue } \\ \text { V. } & \text { Diarrhea } \\ \text { VI. } & \text { Headache } \\ \text { VII. } & \text { Nausea } \\ \text { VIII. } & \text { Edema }\end{aligned}$

9. Effect of dysmenorrhea on activities :

1) No activity limited

2) Sleep disturbed

3) Adversely affects mood 
4) Miss the class

5) Affects other activities

10. Management strategies :

1. Rest

2. Treatment and drugs as per doctor's advice

3. Self medication

4. Hot bags

5. Other measures

The sample size was 143 and all the students had completed the questionnaires completely within given time. The response rate was $100 \%$. The student with history of recent surgery and the pelvic inflammatory disease(PID) were excluded.

A complete questionnaires were coded and entered in the statistical package of social science (SPSS) software version 10.0. Descriptive statistics was used to determine mean age of participants, age at menarche, prevalence of dysmenorrhea, management options and activities affected by the condition.

The categorical data were analyzed by the chi-square test and $\mathrm{P}$ value was calculated to determine the significant association.

OBSERVATIONS AND RESULTS : The mean age of the participants was 19.1 years and mean age of the menarche was 13.2 years.

Table 1: Grading of severity of dysmenorrhea

\begin{tabular}{|l|l|l|l|l|}
\hline Grade & Definition & $\begin{array}{l}\text { Working } \\
\text { ability }\end{array}$ & $\begin{array}{l}\text { Systemic } \\
\text { symptoms }\end{array}$ & $\begin{array}{l}\text { Analgesics } \\
\text { required }\end{array}$ \\
\hline 0 & painless & Not affected & None & Not required \\
\hline 1 & $\begin{array}{l}\text { painful but not inhibits normal } \\
\text { activity }\end{array}$ & $\begin{array}{l}\text { Rarely } \\
\text { affected }\end{array}$ & None & Rarely required \\
\hline 2 & $\begin{array}{l}\text { Daily activity affected \& required } \\
\text { analgesics which gives relief }\end{array}$ & $\begin{array}{l}\text { Moderately } \\
\text { affected }\end{array}$ & Few & Required \\
\hline 3 & $\begin{array}{l}\text { Activity clearly inhibited. Poor } \\
\text { effect of analgesics }\end{array}$ & $\begin{array}{l}\text { Clearly } \\
\text { inhibited }\end{array}$ & Apparent & Poor effect \\
\hline
\end{tabular}

The severity of dysmenorrhea was determined by the multidimensional scoring system based on the pain, activities limited and medications taken.

Table 2: Impact of dysmenorrhea on daily activities

\begin{tabular}{|l|l|l|l|l|}
\hline & \multicolumn{4}{|l|}{ Dysmenorrhea grade } \\
\hline Effects on daily activities & Grade 0 & Grade 1 & Grade 2 & Grade 3 \\
\hline No activities limited & 16 & 51 & 5 & 1 \\
\hline Sleep disturbed & 2 & 20 & 19 & 1 \\
\hline Adversely affects mood & 1 & 22 & 25 & 1 \\
\hline Miss the class & 0 & 5 & 15 & 4 \\
\hline Affects other activities & 1 & 6 & 3 & 3 \\
\hline
\end{tabular}

Table 2 shows effect of dysmenorrhea on activities of affecting women. Sleep disturbance, mood change, missing the class and other daily activities were affected significantly as the severity of dysmenorrhea increases. The $p$ value is $<0.0001$ (chi square 73.663 ) suggests the test is significant. 
Table 3: Management strategies and grading of the dysmenorrhea

\begin{tabular}{|l|l|l|l|l|}
\hline & \multicolumn{5}{|l|}{ Dysmenorrhea grade } \\
\hline Management strategies & Grade 1 & Grade 2 & Grade 3 & Grade 4 \\
\hline Rest & 19 & 1 & 2 & 0 \\
\hline Consult the doctor & 78 & 7 & 5 & 2 \\
\hline Hot bags & 33 & 13 & 10 & 14 \\
\hline Self medication & 4 & 4 & 2 & 0 \\
\hline
\end{tabular}

Table 3 shows the relationship between the grading of dysmenorrhea and the management strategies to alleviate their symptoms. Chi-square value is 43.753 (p value < 0.0001).

DISCUSSION : The mean age of menarche was $13.2 \%$ which correlates with the Kishan Verma study(1). This study showed the high prevalence of dysmenorrhea among the medical students in $87 \%(n=143)$. The study correlates with the previously done study in adolescent girls by Banikarim et al (85\%) (2). There is some difference from other studies which might be due to highly selected subject group. The other issues regarding this study is that there is no any universally accepted and properly defined grading of dysmenorrhea. Moreover pain associated with dysmenorrhea is difficult to measure as it is usually accompanied by other unpleasant sensations and also the reaction component affects the judgement of pain. It should be regarded as multidimensional phenomenon.

This syndrome of dysmenorrhea encompass a wide variety of physical as well as psychological symptoms. In our study the mood change was the most frequently reported complain among the sufferers. Backache, stomach cramps, fatigue, headache, nausea, diarrhea, edema were the other associated symptoms in descending order noticed in our study. There was no relationship between the age of menarche and the prevalence and severity of dysmenorrhea this is contrast findings by the Sundell et al in which prevalence and severity of dysmenorrhea and significantly affected by the age of menarche(3).

Dysmenorrhea is the cause of recurrent short term class absenteeism and restriction in the daily activities in adolescent girls(4,5). Around $15 \%$ of women experience monthly menstrual pain severe enough to prevent the normal daily activities at home, class and workplace. In our study $16.7 \%$ of respondents with dysmenorrhea missed classes. 29.3\% reported limitation of sleep and 34.2\% had mood changes which affected concentration in class and the future performance. Though dysmenorrhea is not the life threatening condition, monthly recurrence of severe symptoms represent a significant morbidity with profound negative impact on day to day life with compounding emotional distress brought on by the pain.

The overall physician consultation rate was $17.4 \%$. This low rate specially in the medicos showed that still most of the women believe that the painful periods are normal female phenomena(6). Rest was the commonest option for overcoming the situation which correlates with the loss of daily activities and weak performance. The practice of self medication is also common (7).

There were some limitations of our study. The major limitation was that the study was done in first year medical students so the findings may not be the same for girls from the other segment of group. The physical examination was not done to identify the secondary dysmenorrhea and so secondary dysmenorrhea was not included in our study. 
CONCLUSION AND RECOMMENDATION : High prevalence rate of dysmenorrhea among the medical students requires attention. Though the subject group was medicos, education is vital in ensuring that dysmenorrhea should no longer be considered as a normal female exercise. Physician consultation must be promoted for dysmenorrheic women. Self medication practices should be minimized. Further studies among the other group of population should be conducted to understand its prevalence as well as impact at individual and social level. Adolescent girls should be encouraged to consult the doctor for their disturbing various menstrual problems.

\section{REFERENCES:}

1. Kishan Verma; annals of human biology 1990 : vol $17: 159-162$.

2. Banikarim C, Chackro MR, KeldeR SH, Prevalence and impact of dysmenorrheal in adolescents. Arch pediatric adolescent medicine $2000: 154: 1226-9$.

3. Sundell G Millstone, Andersch B. Factors influencing prevalence and severity of dysmenorrhea in young women. Br J obs gyn1990; 97 : 588-594.

4. Dawood MY, Primary dysmenorrhea : Advance in pathogenesis and management. Am J Obst -gyn 2006; 108, 428-444.

5. French L. Dysmenorrhea. Am fam physician 2005; $71: 285-291$.

6. Johnson J Level of knowledge among the adolescent girls regarding treatment effectiveness in dysmenorrheal. J of adolescent health care $1988 ; 9$ : 198-402.

7. Ohde S Takuda. Dysmenorrhea among Japanese women. Int J Gyn Obs $2008 ; 100: 13$ -17 .

\section{Graph 1 : Percentage wise distribution of dysmenorrheal grade}

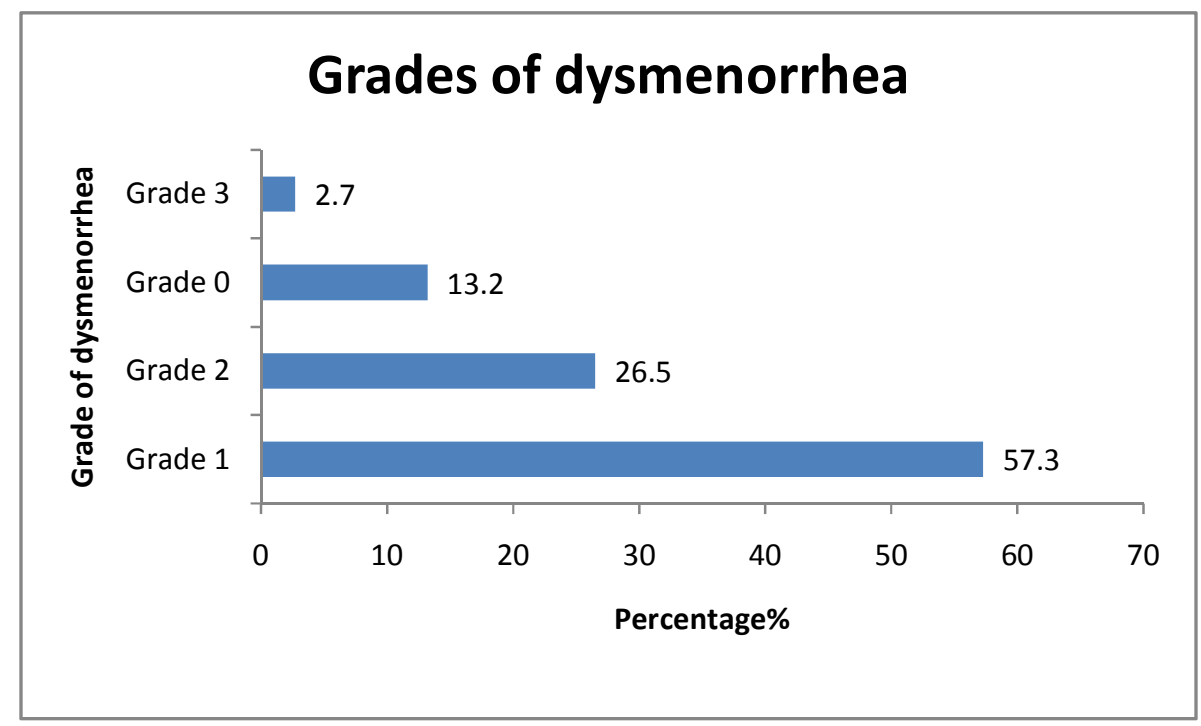

Graph 1 shows the prevalence of dysmenorrhea was 87\% while 13\% experienced no dysmenorrhea $(n=143)$. The most common type of dysmenorrhea was grade1 $(57.3 \%)$ and least common type was grade $3(2.7 \%$.) 
Graph 2 : Percentage of dysmenorrheic women who suffered from associated symptoms

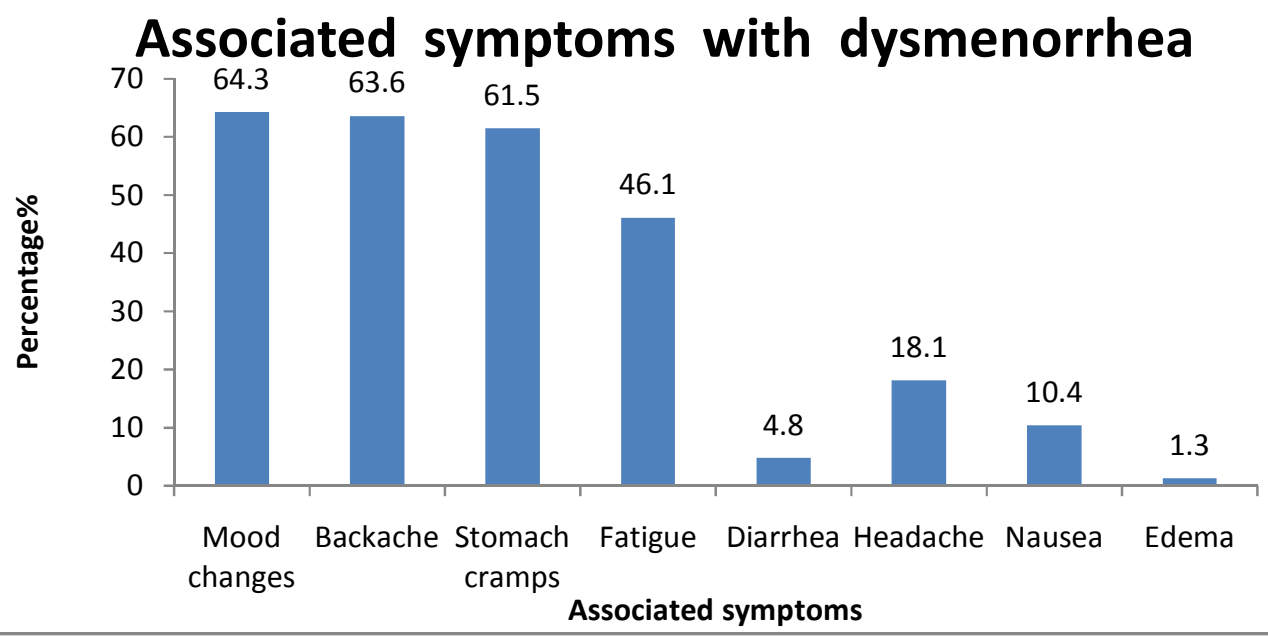

Graph 2 shows reported symptoms associated with the dysmenorrhea. The most common symptoms were mood change(64.3\%), backache(63.6\%), stomach cramps(61.5\%) and fatigue(46.1\%).

Graph 3: percentage of management strategies choose

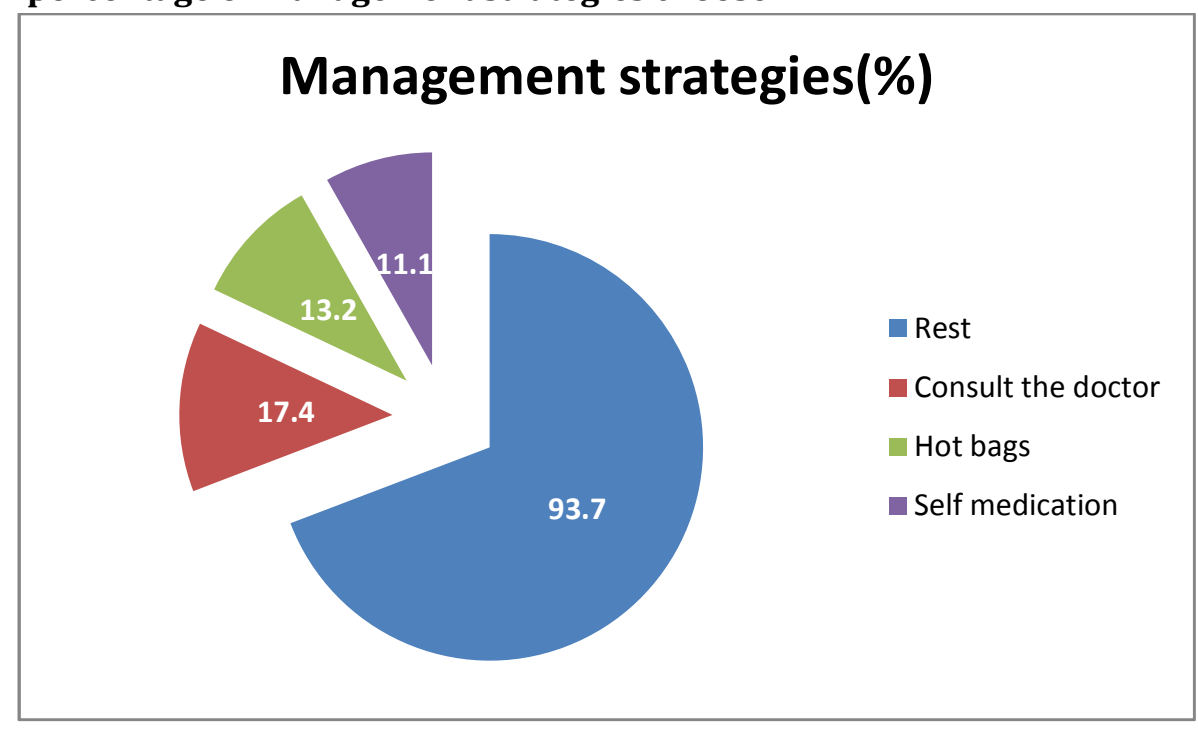

Graph 3 shows that Rest was the most common management strategy practiced (93.7\%), while $17.4 \%$ of girls had consulted the doctor for medication and $11.1 \%$ relied on self medication...Hot bags were also popular in $13.2 \%$. 